\title{
Unofficial toponyms in the language consciousness of Yaroslavl residents (on the example of the toponym Bragino)
}

\author{
Y. S. Potyomkina ${ }^{1}$, M. V. Shamanova ${ }^{1}$
}

${ }_{1}^{1}$ P. G. Demidov Yaroslavl State University, 14 Sovetskaya str., Yaroslavl 150003, Russian Federation

DOI: $10.18255 / 2412-6519-2021-2-204-211$

Research Article Full text in Russian

The article presents a psycholinguistic description of unofficial toponyms of Yaroslavl on the example of one of them. Based on the data of a free associative experiment, the associative fields of the unofficial toponym Bragino were formed in two age groups of subjects: from 18 to 30 years and from 30 to 80 years. When comparing the obtained associative fields, their core and periphery, and semantic groups, the peculiarities of understanding this lexeme by different age groups were revealed. It is shown that the psycholinguistic description of the analyzed lexeme differs in two groups of subjects: the core of the field partially coincides, semantic groups of associative fields overlap, but most of them are different in volume, small semantic groups are relevant only in one group of subjects. As a part of the obtained associative fields, evaluation reactions were identified, both positive and negative. It is shown that evaluative reactions are more common in the youth sphere, but negative-evaluative reactions are superior to positive-evaluative ones in both groups of subjects. In general, the study allows us to draw conclusions about the development of the unofficial toponym by Yaroslavl residents and the similarity and differentiation of associative fields in different age groups.

Keywords: tomonym; unofficial toponym; language consciousness; associative experiment; associative field; semantic group

INFORMATION ABOUT THE AUTHORS

$$
\begin{array}{r|l}
\begin{array}{r}
\text { Potyomkina Yulia.S.. } \\
\text { (correspondence author) }
\end{array} & \begin{array}{l}
\text { E-mail: potyomkina.yuliya@yandex.ru } \\
\text { Student }
\end{array} \\
\text { Shamanova Marina V. } & \begin{array}{l}
\text { E-mail: mshamanova@mail.ru } \\
\text { Doc. Sc. (Philology), Associate Professor }
\end{array}
\end{array}
$$

Funding: P. G. Demidov Yaroslavl State University, project VIP-011.

For citation: Potyomkina Y. S., Shamanova M. V. Unofficial toponyms in the language consciousness of Yaroslavl residents(on the example of the toponym Bragino) // Social'nye i gumanitarnye znanija. 2021. Vol. 7, No 2. P. 204-211. (in Russ.)

(C) Potyomkina Y. S., Shamanova M. V., 2021

This is an open access article under the CC BY license (https://creativecommons.org/licenses/by/4.0/) 


\title{
Неофициальные топонимы в языковом сознании ярославцев (на примере топонима Брагино)
}

\author{
Ю. С. Потемкина ${ }^{1}$, М. В. Шаманова ${ }^{1}$
}

1Ярославский государственный университет им. П. Г. Демидова, ул. Советская, 14, Ярославль, 150003, РФ

DOI: 10.18255/2412-6519-2021-2-204-211

Научная статья УДК 811.161.1

Полный текст на русском языке

В статье представлено психолингвистическое описание неофициальных топонимов г. Ярославля на примере одного из них. На базе данных свободного ассоциативного эксперимента сформированы ассоциативные поля неофициального топонима Брагино в двух возрастных группах испытуемых: от 18 до 30 лет и от 30 до 80 лет. При сопоставлении полученных ассоциативных полей, их ядра и периферии, семантических групп были выявлены особенности осмысления данной лексемы различными возрастными группами. Показано, что психолингвистическое описание анализируемой лексемы в двух группах испытуемых отличается: ядро поля совпадает частично, семантические группы ассоциативных полей пересекаются, но большинство из них оказываются различными по объёму, небольшие семантические группы являются актуальными только в одной группе испытуемых. В составе полученных ассоциативных полей были выявлены оценочные реакции, как положительные, так и отрицательные. Показано, что оценочные реакции более распространены в молодежной сфере, однако отрицательно-оценочные реакции превосходят положительно-оценочные в обеих группах испытуемых. В целом проведенное исследование позволяет сделать выводы об освоенности неофициального топонима ярославцами и сходстве и дифференцированности ассоциативных полей в различных возрастных группах.

Ключевые слова: топоним; неофициальный топоним; языковое сознание; ассоциативный эксперимент; ассоциативное поле; семантическая группа

ИНФОРМАЦИЯ ОБ АВТОРАХ

\begin{tabular}{r|l} 
Потемкина, Юлия Сергеевна & $\begin{array}{l}\text { E-mail: potyomkina.yuliya@yandex.ru } \\
\text { (автор для корреспонденции) } \\
\text { Магистрант }\end{array}$ \\
Шаманова, Марина Владимировна & $\begin{array}{l}\text { E-mail: mshamanova@mail.ru } \\
\text { Доктор филологических наук, доцент, завкафедрой общей } \\
\text { и прикладной филологии }\end{array}$
\end{tabular}

Финансирование: ЯрГУ, проект № ВИП-011

Для цитирования: Потемкина Ю. С., Шаманова М. В. Неофициальные топонимы в языковом сознании ярославцев (на примере топонима Брагино) // Социальные и гуманитарные знания. 2021. Том 7, № 2. C. 204-211.

(C) Потемкина Ю. С., Шаманова М. В., 2021

Статья открытого доступа под лицензией СС BY (https://creativecommons.org/licenses/by/4.0/) 
Объектом исследования в данной статье является один из неофициальных топонимов г. Ярославля.

В толковых словарях русского языка дается примерно одинаковое значение термина «топоним»: «Собственное название отдельного географического места (населенного пункта, реки, озера, горы, урочища и т. п.)» [1, с. 642; 2, с. 1332].

Научное определение термина встречаем в «Энциклопедическом словаресправочнике лингвистических терминов и понятий»: «Топоним (греч. topos «место» +onyma «имя». Слово или краткое словосочетание, применяемое для наименования какого-л. географического объекта, используемое как имя собственное с учетом языка, письменности и традиций того или иного народа...» [3, с. 216].

А. М. Маракуев в «Кратком очерке топонимики как географической дисциплины» дает следующее определение топониму: это имя собственное, которое в существующем контексте с учетом места, времени, языка и письменности служит для отличия одного какого-либо географического объекта от других географических объектов [4, с. 32]. Таким образом, определение термина выходит за рамки лингвистических дисциплин.

Различают официальные и неофициальные топонимы. Официальные топонимы встречаются в словарях, энциклопедиях, справочниках, на картах.

Под неофициальными топонимами вслед за О. А. Шариповой мы будем понимать устойчивые выражения, которые не закреплены в словарях и функционируют в городской речи как неофициальные названия географических объектов [5, c. 203]. Неофициальным топонимам посвящен ряд работ, как на материале русских наименований географических объектов, так и на материале иностранных [6; 7; 8; 9 и др.].

Официальные и неофициальные топонимы обладают рядом важных отличий. Во-первых, неофициальные топонимы не кодифицированы, не нормированы, употребляются, в отличие от официальных топонимов, только в устной обиходно-бытовой речи, зачастую обладают эмоционально-оценочной окраской, поэтому их называют также речевыми топонимами. Во-вторых, неофициальные топонимы встречаются в речи жителей определенного населенного пункта, поэтому их называют регионализмами, локализмами, региолектами и т. п. В-третьих, официальные топонимы, как правило, имеют длительную историю, а неофициальные топонимы могут обладать признаком как историчности, так и динамичности.

Характеризуя неофициальные топонимы, О. А. Шарипова отмечает, что «это не просто лексика и фразеология, характеризующая городские объекты, а лексика особого рода, изучение которой предполагает различные аспекты: социолингвистический, психолингвистический, лингвокультурологический, этнолингвистический и др.» [5, с. 203-204].

При исследовании неофициальных топонимов г. Ярославля мы использовали один из психолингвистических методов, а именно свободный ассоциативный эксперимент.

В «Большом психологическом словаре» дано определение ассоциативному эксперименту как особому методу исследования мотивации личности и как приему, направленному на выявление ассоциаций, сложившихся у индивида в его предшествующем опыте [10, с. 26]. С. В. Архипова утверждает, что «ассоциативный эксперимент является наиболее разработанной техникой психолингвистического анализа семантики». Он вскрывает объективно существующие в психике носителя 
языка семантические связи слов, языковые стереотипы - все то, что помогает впоследствии обобщить как «специфические черты менталитета» $[11$, с. 6].

Нами при изучении семантики неофициальных топонимов были использованы психолингвистические методы.

Испытуемым предлагалось следующее задание: прочитать предлагаемый список слов и написать первую пришедшую на ум реакцию на данное слово. Если не одно слово не вспоминается при прочтении стимула, испытуемые должны были поставить прочерк.

Материалом данного исследования послужили реакции, полученные в результате свободного ассоциативного эксперимента на слово-стимул Брагино.

В психолингвистическом эксперименте приняли участие 227 человек: молодежь Ярославля в возрасте от 18 до 30 лет (I возрастная группа) и взрослые мужчины и женщины в возрасте от 30 до 80 лет (II возрастная группа).

По результатам свободного ассоциативного эксперимента были составлены ассоциативные поля на предложенные в анкете стимулы в разных возрастных группах испытуемых (сохранены орфография и пунктуация анкет).

\section{I возрастная группа}

БРАГИНО 127: далеко 18; гопники 9; дом 8; район 7; криминал, ТЦ «Космос» (Космос) 4; глушь, здесь (БРЗД) 3; бандит (бандиты), Дзержинский р-н, Женя, практика, преступность, пробки, ужас 2; алкоголь, Альтаир, Артемка, бабуля, батуты, беднота, биомусор, болото, бродит, Бродягино, бутылка, Гагарин, грабеж, далекий забытый уголок, деревня, детская больница, долгая дорога, дочь маминой подруги, друзья, завод, каток, конечная, культура, Лёха, любовь, Люся, магазин, маршрутка, ностальгия из детства, овраг, опасно, опасное местечко но приспособиться можно, опасность, отшельники, отшиб города, пацанчики, переход, подруга, рынок, смерть, спокойствие, там убивают людей, темно, тетя, трамвай, удаленность, уют, фабричный район, хрущевки 1.

Всего было получено 119, реакций, из них различных - 65. Отсутствовали реакции в 8 анкетах.

Достаточное количество различных реакций (65), на наш взгляд, говорит о разносторонней освоенности неофициального топонима в языковом сознании ярославской молодежи. Небольшое количество анкет, в которых реакции отсутствовали, подчеркивает освоенность неофициального топонима Брагино.

Ассоциативные реакции были распределены по семантическим группам, которые мы расположили в порядке убывания общего количества реакций в группе:

Пространственная характеристика: далеко 18; глушь, здесь (БРЗД) 3; далекий забытый уголок, деревня, долгая дорога, отшельники, отшиб города, удаленность 1. Всего 30 реакций.

Определение района как неблагополучного: гопники 9; криминал 4; бандит (бандиты), преступность 2; алкоголь, беднота, бутылка, грабеж, опасно, опасное местечко но приспособиться можно, опасность, пацанчики, смерть, там убивают людей 1 . Всего 27 реакций.

Указание на городские и природные объекты: ТЦ «Космос» (Космос) 4; Альтаир, батуты, болото, детская больница, завод, каток, магазин, овраг, переход, рынок, трамвай, фабричный район, хрущевки 1. Всего 17 реакций. 
Связь с домом и семьей, знакомыми: дом 8; бабуля, дочь маминой подруги, друзья, ностальгия из детства, подруга, тетя 1. Всего 14 реакций.

Эмоции, впечатления, субъективные ощущения, оценки: ужас 2; любовь, спокойствие, темно, уют 1 . Всего 6 реакций.

Характеристика дорожных условий: пробки 2. Всего 2 реакции.

Характеристика с помощью различных видов транспорта: конечная, маршрутка 1 . Всего 2 реакции.

Не были распределены в семантические группы созвучные реакции: бродит, Бродягино 1. Всего 2 реакции.

Некоторые реакции не поддаются интерпретации, в частности, реакции, связанные с конкретными личными впечатлениями и опытом испытуемых: Женя, практика 2; Артемка, биомусор, Гагарин, культура, Лёха, Люся 1. Всего 10 реакций.

Семь реакций являются определением неофициального топонима Брагино район. Двое испытуемых дали в качестве реакции официальный топоним: Дзержинский $р$-н.

На топоним было дано 37 оценочных реакций, из них две положительных (спокойствие, уют 1) и 35 отрицательных (гопники 9; криминал 4; глушь 3; бандит (бандиты), пробки, преступность 2; алкоголь, беднота, грабеж, далекий забытый уголок, деревня, опасно, опасное местечко но приспособиться можно, опасность, отшиб города, пацанчики, смерть, там убивают людей, ужас 1). Таким образом, отрицательно-оценочных реакций почти в восемнадцать раз больше, чем положительно-оценочных.

\section{II возрастная группа}

БРАГИНО 100: брага, пробка, пруды «очки» 8; деревня, живу 7; мой район 6; Альтаир, спальный район 4; здесь 3; больница, высотки, город, дом (мой дом), муравейник, Норское, район 2; 2-е Брагино, болото, большая деревня, бражка, бродягино, выпивка, говно, гопники, Дзержинский район, дома, здорово, зеленая зона, Космос, Моторный завод, нет дорог вообще, одноклассница, озеро, окраина, очень неудобно, панелька, парк Победы, поселок, промзона, Пятерка, работа «мечты», разбой, родное, трамвай, ул. А. Невского, Ярославль 1.

Всего реакций - 99, из них различных - 46. В 3 анкетах реакции отсутствовали.

Достаточное количество различных реакций свидетельствует о разносторонней освоенности неофициального топонима в языковом сознании взрослого населения. Небольшое количество анкет, в которых реакции отсутствовали, подчеркивает освоенность неофициального топонима Брагино.

Ассоциативные реакции были распределены по семантическим группам, которые мы расположили в порядке убывания общего количества реакций в группе:

1. Указание на городские и природные объекты: пруды «очки» 8; Альтаир 4; больница, высотки 2; болото, дома, зеленая зона, Космос, Моторный завод, озеро, панелька, парк Победы 1. Всего 24 реакции.

2. Пространственная характеристика: деревня 7; здесь 3; город, Норское 2; 2-е Брагино, окраина, поселок, промзона, ул. А. Невского, Ярославль 1. Всего 20 реакций.

3. Связь с домом и семьей, знакомыми: живу 7; мой район 6; дом (мой дом) 2; одноклассница 1. Всего 16 реакций. 
4. Характеристика дорожных условий: пробка 8; нет дорог вообще 1. Всего 9 реакций.

5. Эмоции, впечатления, субъективные ощущения, оценки: большая деревня, муравейник, говно, здорово, очень неудобно, родное 1. Всего 6 реакций.

6. Определение района как неблагополучного: выпивка, гопники, разбой 1. Всего 3 реакции.

Не были распределены в семантические группы созвучные топониму реакции: брага 8; бражка, бродягино 1. Всего 10 реакций.

Единичная реакция работа «мечты» не составила семантическую группу, но она связана с определением района как места работы. Также единичная реакция трамвай не составила семантическую группу, но она связана с характеристикой района с помощью различных видов транспорта.

13 реакций были непосредственным определением неофициального топонима Брагино - район (мой район 6; спальный район 4; район 2). Один испытуемый дал в качестве реакции официальный топоним: Дзержинский район.

Одна реакция дана ошибочно, она связана с другим районом Ярославля: Пятерка 1.

На топоним было дано 17 оценочных реакций, из них 2 положительных (здорово, родное 1) и 15 отрицательных (пробка 8; большая деревня, выпивка, говно, гопники, нет дорог вообще, очень неудобно, разбой 1). Таким образом, отрицательнооценочных реакций почти в восемь раз больше, чем положительно-оценочных.

Анализ ассоциативных полей двух возрастных групп показал, что ядро поля не совпадает в этих группах. Приведем наиболее частотные реакции в таблице 1.

Таблица 1

\section{Ядро ассоциативного поля неофициального топонима Брагино в двух возрастных группах}

\begin{tabular}{|l|l|}
\hline \multicolumn{1}{|c|}{ От 18 до 30 лет } & \multicolumn{1}{|c|}{ Старше 30 лет } \\
\hline далеко 18 & брага, пробка, пруды «очки» 8 \\
\hline гопники 9 & деревня, живу 7 \\
\hline дом 8 & мой район 6 \\
\hline
\end{tabular}

Ядро поля в молодежном ассоциативном поле четко выражено, реакция, относящаяся к центру ядра, имеет частотность, вдвое превышающую последующую. Во второй возрастной группе ядро и периферия имеет нечеткие, размытые границы.

Молодежь определяет Брагино с помощью абстрактной пространственной характеристики далеко, а взрослые реципиенты дают более конкретные реакции и связывают район с природным объектом (пруды «очки») и дорожной ситуацией (пробки). Ядерные реакции у обеих групп связаны с домом - дом у студентов и живу, мой район у взрослых. Следует отметить, что реакции гопники, дом, пробки присутствуют в обоих ассоциативных полях, однако размещаются в различных зонах данных полей. 
Шесть семантических групп совпадают в двух группах испытуемых: «Пространственная характеристика» (30 и 21 реакция соответственно у молодежи и испытуемых старше 30 лет); «Указание на городские и природные объекты» (17 и 25 реакций соответственно); «Связь с домом и семьей, знакомыми» (14 и 16 реакций); «Эмоции, впечатления, субъективные ощущения, оценки» (по 6 реакций в каждой возрастной группе); «Определение района как неблагополучного» (27 и 3 реакции); «Характеристика дорожных условий» (2 и 9 реакций). Таким образом, большинство семантических групп совпадает.

Однако самая объемная группа у испытуемых от 18 до 30 лет - «Пространственная характеристика», а у испытуемых от 30 до 80 лет - «Указание на городские и природные объекты», что говорит о более конкретном восприятии неофициального топонима Брагино языковым сознанием взрослого населения.

У «взрослых» испытуемых семантическая группа «Определение района как неблагополучного» представлена менее объемно (3 реакции), в молодежной группе - 27 реакций. Такую асимметричность можно объяснить тем, что гопниками (ядерная реакция в молодежной возрастной группе) чаще всего называют молодых людей. Также во II возрастной группе отсутствуют реакции, входящие в семантическую группу «Характеристика с помощью различных видов транспорта», хотя и в молодежном языковом сознании она представлена всего двумя реакциями.

Внутри семантических групп есть несовпадающие реакции. У взрослых реципиентов отмечается реакция пруды «очки» с достаточно высоким индексом яркости (8), что подчеркивает более конкретное и разнообразное восприятие неофициального топонима Брагино.

Оценочных реакций среди молодежи в 2,2 раза больше, чем у испытуемых более старшего возраста: 37 и 17 реакций соответственно. Такая разница, на наш взгляд, объясняется наличием у молодых реципиентов реакций, относящихся к семантической группе «Указание на криминальность района», которые содержат отрицательную оценку. В обеих возрастных группах преобладают отрицательно-оценочные реакции - 35 и 15 реакций соответственно.

Отметим, что взрослые реципиенты ассоциируют неофициальный топоним с собой, выражая реакцию с помощью притяжательного местоимения (мой район 6; дом (мой дом) 2). Такие реакции свойственны мужчинам и женщинам от 45 лет. У студентов аналогичных реакций не выявлено.

Таким образом, сравнительный анализ показал, что неофициальный топоним Брагино достаточно хорошо и дифференцированно освоен различными возрастными группами испытуемых.

\section{Ссылки / References}

1. Ожегов С. И. Толковый словарь русского языка. М.: Мир и образование; Астрель; Оникс, 2012. 736 с.

2. Большой толковый словарь русского языка / Гл. ред. С. А. Кузнецов. СПб: Норинт, 2000. 1536 c.

3. Энциклопедический словарь-справочник лингвистических терминов и понятий. Русский язык: в 2 т. / А. Н. Тихонов, Р. И. Хашимов, Г. С. Журавлева и др.; под общ. ред. А. Н. Тихонова и Р. И. Хашимова. Т. 1. М.: Флинта: Наука, 2008. 840 с. 
4. Маракуев А. М. Краткий очерк топонимики как географической дисциплины // Учен. записки Казах. ун-та. Сер. «Геология и география». Алма-Ата, 1954. Т. 18. Вып. 2.

C. 29-72.

5. Шарипова О. А. Неофициальные топонимы как подсистема языка города // Ярославский педагогический вестник. 2012. № 4. C. 203-206. URL: https://cyberleninka.ru/article/n/neofitsialnye-toponimy-kak-podsistema-yazyka-goroda (дата обращения: 26.05.2021).

6. Ахметова М. В. Неофициальная топонимика Российского Севера (Карелия и Ленинградская область) в электронных источниках // Ученые записки Петрозаводского государственного университета. 2013. № 3. С. 54-59.

7. Борейко Т. С., Шпак Е. А. Неофициальная топонимика современного города (на примере Омска) // Гуманитарные исследования. 2013. № 1. URL:

https://cyberleninka.ru/article/n/neofitsialnaya-toponimika-sovremennogo-goroda-naprimere-omska/viewer (дата обращения: 26.05.2021).

8. Рослякова Е. С. Неофициальные топонимы крупных городов США: способы образования и связь с культурой // Актуальные проблемы филологии и методики преподавания иностранных языков. 2017. Том 11. C. 110-113. URL:

https://repo.nspu.ru/bitstream/nspu/2464/1/neoficialnye-toponimy-krupnyh-go.pdf (дата обращения: 26.05.2021).

9. Субиркина Н. Ю. О языковом творчестве (на примере неофициальных названий Франции и Англии) // Вестник ВГУ. Серия: Филология. Журналистика. 2017. № 3. C. 69-71. URL: http://www.vestnik.vsu.ru/pdf/phylolog/2017/03/2017-03-13.pdf (дата обращения: 26.05.2021).

10. Большой психологический словарь / Сост. и общ. ред. Б. Г. Мещеряков, В. П. Зинченко. СПб.: Прайм-Еврознак, 2003. 632 с.

11. Архипова С. В. Ассоциативный эксперимент в психолингвистике // Вестник БГУ. Язык, литература, культура. 2011. № 11. URL: https://cyberleninka.ru/article/n/ assotsiativnyyeksperiment-v-psiholingvistike (дата обращения: 19.06.2019). 